\title{
FITOTERAPIA RACIONAL: ASPECTOS TAXONÔMICOS E AGROECOLÓGICOS
}

\author{
Mariana Possamai Della Colle ${ }^{1}$, \\ Angela Erna Rossato ${ }^{2}$, \\ Roberto Recart dos Santos ${ }^{3}$, \\ Vanilde Citadini-Zanette ${ }^{4}$
}

\section{INTRODUÇÃO}

As civilizações mais antigas, de todas as culturas, utilizavam seus conhecimentos populares para desenvolver seus próprios sistemas terapêuticos e, até hoje, muitas pessoas ainda têm como única opção a medicina popular (OLIVEIRA et al., 2011; SHARMA et al., 2012) .

Sendo assim, a valorização da cultura do uso de plantas que apresentam propriedades terapêuticas vêm se desenvolvendo em consequência do interesse por formas de tratamento natural (MOREIRA; SALGADO; PIETRO, 2008). Com isso, os relatos populares vêm contribuindo para a disseminação terapêutica destes vegetais, os quais são indicados com base em experiências relatadas com o uso (LORENZI; MATOS, 2008).

Em sociedades tradicionais, a transmissão oral é o principal modo pelo qual o conhecimento se perpetua (ROSSATO et al., 2012).

O Brasil por ser um país com uma grande biodiversidade junto à riqueza etnocultural possui um inestimável conhecimento tradicional agregado ao uso de plantas medicinais, apresentando competência para 0 desenvolvimento de pesquisas com âmbito em tecnologias e terapêuticas apropriadas (MINISTÉRIO DA SAÚDE, 2006).

Assim entra a fitoterapia caracterizando-se pelo tratamento de doenças com uso de plantas medicinais e suas diferentes formas farmacêuticas sem a utilização de seus princípios isolados (FIRMO et al., 2011).

\footnotetext{
${ }^{1}$ Mariana Possamai Della Colle. Acadêmica do Curso de Ciências Biológicas, UNAHCE, Universidade do Extremo Sul Catarinense (UNESC) mariana.colle@hotmail.com.

2 Angela Erna Rossato. Professora/Pesquisadora (UNASAU/UNESC) aer@unesc.net

${ }^{3}$ Roberto Recart dos Santos. Professor/Pesquisador (UNAHCE/UNESC) rrs@unesc.net

${ }^{4}$ Vanilde Citadini- Zanette. Professora/Pesquisadora (UNAHCE/UNESC) vcz@unesc.net
} 
Um dos pontos críticos no uso de planta medicinais é a sua identificação botânica, pois somente o conhecimento pelos nomes populares podem trazer confusões no uso da planta correta, devendo conhecer seu nome científico. Outra condição para que as plantas utilizadas sejam aproveitadas em todas as potencialidades de uso é a forma de cultivo, determinante para o desenvolvimento, produtividade e concentração dos teores dos princípios ativos desejados (CITADINIZANETTE et al., 2015).

Sendo assim, ressalta-se a importância do estabelecimento de compêndios especializados para descrever qual a melhor forma de utilização dessas plantas no alívio de alguma sintomatologia (PANIZZA, 1997).

Pelo exposto acima, nossa proposta é integrar a Comunidade e a Universidade com a troca entre o saber popular e o conhecimento científico visando a promoção do uso racional da fitoterapia, incentivando desta forma a pesquisa científica com plantas medicinais pelo resgate do conhecimento popular.

\section{METODOLOGIA}

O projeto "Fitoterapia Racional: aspectos etnobotânicos, taxonômicos, agroecológicos e terapêuticos" está sendo desenvolvido na Universidade do Extremo Sul Catarinense (UNESC), sediada em Criciúma, Estado de Santa Catarina, onde mensalmente reúnem-se os profissionais da UNESC e as Agentes da Pastoral da Saúde, Regional Sul 4, para troca de informações sobre as plantas medicinais.

A planta escolhida para o estudo mensal é levada até a UNESC, onde ocorre a identificação botânica da espécie. Em seguida esta informação é repassada para todos os acadêmicos bolsistas, que na sequência realizam junto com os professores pesquisas em bibliografias e sites científicos sobre a planta medicinal, sendo elaboradas apresentações que são repassadas para as agentes nos encontros que ocorrem em todo início de mês. Nestes encontros, a técnica utilizada é a de Grupo Focal (ALBUQUERQUE et al., 2010), empregada como uma estratégia de coleta de informações que privilegia um espaço de interação entre o grupo e o pesquisador.

Por tratar-se de atividade com caráter interdisciplinar, interligando profissionais e saberes de diversas áreas do conhecimento, entre elas as da saúde 
e ambiental, as plantas são estudadas e avaliadas quanto aos aspectos taxonômicos, agroecológicos, etnobotânicos e terapêuticos. Integram a equipe e a sequência das atividades nos encontros: 01 Bióloga e Botânica; 01 Engenheiro Agrônomo; 20-40 Agentes da Pastoral da Saúde; 02 Farmacêuticas.

Anualmente são elaboradas apostilas contendo as informações sobre as plantas estudadas durante o período de um ano, que são entregues às agentes para eventuais consultas. Posteriormente, as agentes que participam dos encontros, repassam as informações recebidas às demais agentes integrantes da Pastoral da Saúde, atingindo em média 730 agentes.

Neste artigo serão abordados somente os aspectos botânicos e agroecológicos das plantas estudadas no período de abril de 2015 a março de 2016.

\section{RESULTADOS}

Os aspectos taxonômicos e agroecológicos das 10 plantas estudadas nos encontros mensais no período determinado estão descritos a seguir:

Cuphea carthagenensis (Jacq.) J.F. Macbr. (Sete - sangrias). Espécie nativa do Brasil, pertencente à família Lythraceae. É uma planta herbácea com aproximadamente $20-50 \mathrm{~cm}$ de altura, ereta e pouco ramificada, caule de coloração avermelhada. Folhas simples, opostas, curto-pecioladas, margens planas, base aguda. Flores com 6 pétalas, de róseas a lilases, alternas, perpendiculares, formando ângulo de quase $90^{\circ}$ graus em relação ao pedicelo. Fruto ampuláceo, inflado quando maduro. Semente em regra de 3-5, pardo-avermelhadas (REITZ, 1969; LORENZI, MATOS, 2002; WANDERLEY, 2002).

Espécie cosmopolita, com preferência à solos úmidos, heliófita com propagação por sementes (PANIZZA, 1997; ARANHA, 2015; LUSA, 2015).

Punica granatum L. (Romã). Espécie exótica, pertencente à família Lythraceae. Espécie arbustiva, de até $3 \mathrm{~m}$ de altura, tronco ereto, muito ramoso. Folhas simples, coriáceas e cartáceas. Flores solitárias, sésseis, munidas de duas brácteas. Fruto do tipo baga, globóide, amarelo com manchas verdes. Sementes irregularmente facetadas com tegumento gelatinoso na superfície (REITZ, 1984; LORENZI et al. 2006; LORENZI, MATOS, 2008). 
Espécie de clima tropical e subtropical, pouco exigente quanto ao tipo de solo, apresenta preferência por locais com sol e a propagação se dá via sementes (LORENZI, 2006; BATISTA et al., 2011; SILVA, 2015).

Phyllanthus tenellus Roxb. (Quebra-pedra). Espécie nativa, pertencente à família Phyllanthaceae. Planta herbácea anual, medindo 0,30-0,60 m de altura, caule fino e cilíndrico. Folhas alternas, dísticas e glabras. Flores unissexuadas. Fruto minúsculo, pedunculado. Sementes ásperas e escuras (CASTRO; CHEMALE, 1995; SILVA JR, 1997; ULYSSÉN; AMARAL, 1997; SMITH et al., 1988; ANVISA, 2015).

Planta de clima tropical e subtropical, pouco exigente ao solo, ocorrência em áreas ruderais, heliófita e a propagação ocorre por mudas e sementes (CASTRO; CHEMALE, 1995; SILVA JR, 1997; SMITH et al., 1988).

Thymus vulgaris L. (Tomilho). Espécie exótica, pertencente à família Lamiaceae. É um subarbusto aromático, lenhoso na base, entouceirado, medindo de $20-30 \mathrm{~cm}$ de altura. Folhas pequenas, opostas, sésseis ou curto-pecioladas. Flores pequenas, zigomorfas reunidas em inflorescência axilar do tipo espiga. Fruto diminuto (CORRÊA; MING; SCHEFFER, 1994; CASTRO; CHEMALE, 1995; LORENZI; MATOS, 2008).

Planta de clima temperado e subtropical, com preferência aos solos mais porosos, propagação através de sementes, estacas, mergulhia ou divisão de touceiras (SILVA JR, 1997; PANIZZA, 1997; MARTINS et al., 2000; RUBIN et al.,2007).

Plantago major L. (Tansagem). Espécie exótica, pertencente à família Plantaginaceae. Planta herbácea, podendo chegar a $30 \mathrm{~cm}$ de altura. Folhas dispostas em roseta basal, com pecíolo longo. Flores dispostas em inflorescência do tipo espiga, cilíndrica e carnosa. Fruto do tipo pixídio, ovóide, contendo em média 30 sementes (SILVA JR, 1997; LORENZI; MATOS, 2008; MOCHIZUKI, 2015).

Planta de clima temperado e subtropical, com preferência por solos arenosos, o plantio deve ser realizado no fim do outono e a propagação se dá por sementes (SILVA JR, 1997; FREITAS et al., 2002). 
Plantago australis Lam. (Tansagem). Espécie nativa, pertencente à família Plantaginaceae. Planta herbácea, perene, com raízes adventícias oriundas de um rizoma. Folhas lanceoladas, pecíolo largo e mais curto que em $\boldsymbol{P}$. major, podendo apresentar-se glabras ou com poucos pelos (RAHN; REITZ, 1996). Flores em inflorescência do tipo espiga.

Espécie de clima temperado e subtropical, com preferência a solos arenosos (FREITAS et al., 2002).

Sedum dendroideum Moc. et Sessé ex DC. (Bálsamo). Espécie exótica, pertencente à família Crassulaceae. Planta herbácea, muito suculenta e ramificada, de $30-60 \mathrm{~cm}$ de altura. Folhas simples, alternas, sésseis. Flores de coloração amarelado intenso, reunidas em inflorescências com numerosas flores (SILVA JR, 1997; LORENZI; SOUZA, 2001; DUARTE; ZANETI, 2002).

Espécie de clima tropical seco, com preferência a solos secos, fofos, areno-siltosos e bem drenados, heliófita e xerófila e sua propagação ocorre por estacas (SILVA JR, 1997; LORENZI; SOUZA, 2001; NASCIMENTO; VIEIRA, 2014).

Buddleja stachyoides Cham. \& Schltdl. (Verbasco). Espécie nativa, pertencente à família Scrophulariaceae. É um arbusto perene, chegando a atingir 0,80-1,60 m. Folhas simples, opostas, sésseis ou subsésseis com margens irregulares. Inflorescência racemosa com $10-30 \mathrm{~cm}$. Flores amarelas. Sementes medindo cerca de $1 \mathrm{~mm}$, com testa esponjosa na base (SILVA JR, 1997; LORENZI; MATOS, 2008; OLIVEIRA, 2012).

Espécie heliófita, com preferência a solos férteis e revolvidos, desenvolvese a pleno sol e multiplica-se através de sementes, sendo que o plantio deve ocorrer no outono e primavera (SILVA JR, 1997).

Annona muricata L. (Graviola). Espécie cultivada no Brasil, pertencente à família Annonaceae. É uma árvore perenifólia medindo de 4-6 $\mathrm{m}$. Folhas simples, alternas, pecioladas, subcoriáceas. Flores solitárias ou em inflorescências paucifloras. Fruto do tipo baga, com superfície ouriçada, pesando em média $5 \mathrm{~kg}$, polpa mucilaginosa. Sementes numerosas, obovoides, com testa dura e coloração marrom (LORENZI et al, 2006; LORENZI; MATOS, 2008; OLIVEIRA, 2012). 
Espécie de clima tropical, sendo altamente adaptada a diferentes tipos de solo, a propagação pode ocorrer de diversas formas como por sementes ou por enxertia, estaquia, alporquia e cultura de tecidos; o amadurecimento dos frutos ocorre entre setembro e janeiro (LORENZI et al., 2006; EMBRAPA, 1999).

Sorghum bicolor (L.) Moench (Vassoura). Espécie exótica, pertencente à família Poaceae. Planta herbácea, anual, medindo entre 1,5-6 $\mathrm{m}$ de altura. Folhas com lâminas de até $8 \mathrm{~cm}$ de largura, base largo-arredondada. Inflorescência terminal paniculada, apresentando uma espiga séssil. Fruto cariopse. Sementes sem proteção (SMITH; WASSHAUSEN; KLEIN, 1982; FERNANDES, 2014).

Espécie com larga adaptabilidade ao clima e solo, propaga-se através de sementes, o plantio deve ser realizado na primavera e floresce durante todo 0 ano (SMITH; WASSHAUSEN; KLEIN, 1982; EMBRAPA, 2008; FERNANDES, 2014).

\section{CONSIDERAÇÕES FINAIS}

Diante do exposto, conclui-se que as interações e as conexões entre o científico e o popular, na busca do terceiro saber, têm apresentado expressiva relevância acadêmico/social, por possibilitar a melhoria da compreensão interdisciplinar sobre a taxonomia, cultivo e a utilização das plantas medicinais. $\mathrm{O}$ uso dessas plantas podem trazer benefícios como também malefícios, por isso o reconhecimento da planta pelo nome científico e a correta identificação botânica tem importância fundamental. Desta forma a UNESC, através do projeto Fitoterapia Racional, compartilha e interage com a Comunidade de forma mútua, pois as Agentes da Pastoral da Saúde conhecendo o valor da identificação botânica e das práticas agroecológicas, podem multiplicar o conhecimento adquirido com a Comunidade interessada na região onde atuam. 


\section{REFERÊNCIAS}

ANVISA. QUEBRA-PEDRA Phyllanthus tenellus herbae. Farmacopéia brasileira. Disponível em:<

http://www.anvisa.gov.br/hotsite/farmacopeiabrasileira/arquivos/cp_240509/quebrapedra\%20tenellus\%20_final_.pdf >. Acesso em:27 mai.2015.

ARANHA, C. et al. Plantas Invasoras de Várzeas no Estado de São Paulo. Disponível em:< http://www.scielo.br/pdf/pd/v3n2/a04v3n2.pdf >. Acesso em: 11 mar.2015.

ALBUQUERQUE, U. P.; LUCENA, R. F. P.; LINS NETO, E. M. F. Seleção dos participantes da pesquisa. In: ALBUQUERQUE, U. P; LUCENA, R. F. P; CUNHA, L. V. F. C. (Orgs.). Métodos e técnicas na pesquisa etnobiológica e etnoecológica. Recife: NUPPEA, 2010. p. 21-37.

BATISTA, P. F et al. Propagação vegetativa de romã em diferentes substratos. Revista Verde (Mossoró-RN-Brasil) v.6,n.4, p.96-100, 2011.

CASTRO, L. O ; CHEMALE, V. M. Plantas medicinais: Condimentares e aromáticas Descrição e cultivo.Guaíba: Agropecuária, 1995.196p.

CITADINI-ZANETTE et al. Fitoterapia Racional: aspectos taxonômicos e agroecológicos. In: BACK, A. C. P; CARDOSO, A. L. (Orgs.). Práticas e Saberes de Extensão. Curitiba: Multideia, 2016. v. 4, 206p.

CORRÊA,C. J; MING, L. C; SCHEFFER, M. C. Cultivo de plantas medicinais, condimentares e aromáticas. 2.ed. Jaboticabal, FUNEP, 1994.

DUARTE, M. R; ZANETI, C. C. Morfoanatomia de folhas de bálsamo: Sedum dendroideum Moc. et Sessé ex DC, Crassulaceae. Revista Lecta, Bragança Paulista. v. 20, n.2, p.153-160.2002.

EMBRAPA. Empresa Brasileira de Pesquisa Agropecuária. A Cultura da Gravioleira (Annona muricata L.).1999.

FERNANDES, P. G. Avaliação agronômica de dois cultivares de sorgo sacarino (Sorghum bicolor (L.) Moench) em Sete lagoas - MG. Doutorado em Produção Vegetal, Centro de Ciências e Tecnologias Agropecuárias- Universidade Estadual do Norte Fluminense Darcy Ribeiro, 2014.

FIRMO, W. C. A. et al. Contexto Histórico, Uso Popular e Concepção Científica sobre Plantas Medicinais. Cadernos de Pesquisa, v.18, n. especial, 2011.

FREITAS, A. G. et al. Atividade Antiestafilocócica do Plantago major L. Revista Brasileira de Farmacologia, v. 12, p. 64-65, 2002. 
LORENZI, H.; BACHER, L.; LACERDA, M.; SARTORI, S. Frutas Brasileiras e Exóticas Cultivadas (de consumo in natura).São Paulo: Instituto Plantarum de Estudos da Flora, 2006.640p.

LORENZI, H.; MATOS, A. F. J. Plantas Medicinais no Brasil: nativas e exóticas. 2.ed. Nova Odessa: Instituto Plantarum, 2008. 544p.

LORENZI, H.; SOUZA, H. M. Plantas Ornamentais no Brasil: Arbustivas, herbáceas e trepadeiras. 3ed. Nova Odessa, SP: Instituto Plantarum, 2001.

LUSA, M. G; BONA, C. Caracterização morfoanatômica e histoquímica de Cuphea carthagenensis (Jacq.) J.F.Macbr. (Lythraceae). Disponível em: http://www.scielo.br/pdf/abb/v25n2/a27v25n2.pdf> Acesso: 16 mar. 2015.

MARTINS, E. R et al. Plantas Medicinais. Viçosa: UFV, 2000. 220p.:il.

MINISTÉRIO DA SAÚDE. Secretaria de Vigilância em Saúde. Departamento de Análise de Situação em Saúde. Saúde Brasil 2006 - Brasília: Ministério da Saúde, 2006. 620 p.

MOCHIZUKI, R. Y. Tanchagem. Fitofar- UEGP. Universidade Estadual de Ponta Grossa, Paraná, Brasil.2015

MOREIRA, T. M. S.; SALGADO, H. R. N; PIETRO, R. C. L. R. O Brasil no Contexto de Controle de Qualidade de Plantas Medicinais. Revista Brasileira de Farmacognosia. 20(3): 435-440, 2010.

NASCIMENTO, I. G; VIEIRA, M. R. S. Manual de Plantas Medicinais: Farmácia Verde. 2014. Disponível em:<http://www.unisantos.br/wpcontent/uploads/2014/02/farmacia-verde-livro.pdf>.Disponível em: 18 ago.2015.

OLIVEIRA, A. K. M et al. Ethnobotanic and traditional medicine of the inhabitants of the sub-region Pantanal Negro and the raizeiros of Miranda and Aquidauna, Mato Grosso do Sul, Brazil. Brazilian Journal of Biology, v. 71, n. 1, supl. 1, p. 283-289, 2011.

OLIVEIRA, C. C. Estudos toxicológicos pré-clínicos e antitumorais do extrato acetônico das folhas de Annona muricata L.174f. Tese (Doutorado) Universidade Federal do Ceará. Fortaleza, 2012.

OLIVEIRA et al. Isolamento do verbacosídeo e validação de método analítico para padronização do extrato bruto das partes aéreas de Buddleja stachyoides Cham. \& Schltdl. (Scrophulariaceae). Química Nova, v. 37, n.2, p.344-348, 2014.

PANIZZA, S. Plantas que curam. 9.ed. São Paulo: IBRASA, 1997. 279p.

REITZ, P. R. Flora llustrada Catarinense. Itajaí/SC.1969.80p. 
REITZ, P. R. Flora llustrada Catarinense. Itajaí/SC.1984.8p.

ROSSATO, A. E et al. Fitoterapia racional: aspectos taxonômicos, agroecológicos, etnobotânicos e terapêuticos. Florianópolis: DIOESC, 2012. v.1.

SHARMA, R. $U$ et al. Medico-religious plants used by the Hajong community of Assam, India. Journal of Ethnopharmacology, v.143, n. 787-800, p.787- 800.2012.

RUBIN, S. et al., Reguladores de crescimento na multiplicação in vitro de Thymus vulgaris L. Revista Brasileira de Biociências. v. 5, supl. 2, p. 480-482, jul. 2007 , Porto Alegre.

SILVA, JR, A. A. Plantas Medicinais EPAGRI (EMPRESA de Pesquisa Agropecuária e Extensão Rural de SC) PROMED (Projeto de Plantas Medicinais), CD Rom. 1997.

SILVA, J. A. T. et al. Biologia romã e biotecnologia: Uma revisão. Scientia Horticulturae. v.160. 2013. p.85-107.

SMITH, L. B; DOWNS, R. J; KLEIN, R. M. Euforbiáceas. In: Flora llustrada Catarinense. Itajaí: Herbário Barbosa Rodrigues 1988.

SMITH, L. B.; WASSHAUSEN, D. C; KLEIN, R. M. Gramíneas. In: Flora llustrada Catarinense. Itájaí- Santa Catarina, 1980.

WANDERLEY, M. G. L.; SHEPHERD, G. J; GIULIETTI, A. M. Flora Fanerogâmica do Estado de São Paulo. vol.2. São Paulo: Editora Hucitec, 2002, 351p. 